\title{
Lipoic acid protects against oxidative stress induced impairment in insulin stimulation of protein kinase B and glucose transport in 3T3-L1 adipocytes
}

\author{
A. Rudich ${ }^{1}$, A. Tirosh ${ }^{2}$, R. Potashnik ${ }^{2}$, M. Khamaisi ${ }^{2}$, N. Bashan ${ }^{2}$ \\ ${ }^{1}$ The S. Daniel Abraham International Centre for Health and Nutrition, Ben-Gurion University of the Negev, Beer-Sheva, Israel \\ ${ }^{2}$ Department of Clinical Biochemistry, Faculty of Health Sciences, Ben-Gurion University of the Negev, Beer-Sheva, Israel
}

\section{Abstract}

Aims/hypothesis. Oxidative stress has been shown to impair insulin-stimulated glucose transporter 4 translocation in 3T3-L1 adipocytes. This study explores the potential of the antioxidant lipoic acid to protect the cells against the induction of insulin resistance when given before exposure to oxidative stress.

Methods. 3T3-LI were exposed for $16 \mathrm{~h}$ to lipoic acid after which cells were exposed for $2 \mathrm{~h}$ to continuous production of $\mathrm{H}_{2} \mathrm{O}_{2}$ by adding glucose oxidase to the culture medium.

Results. These conditions resulted in a $50-70 \%$ reduction in insulin-stimulated glucose transport activity associated with a decrease in reduced glutathione content from $37.4 \pm 3.1$ to $26.4 \pm 4.9 \mathrm{nmol} / \mathrm{mg}$ protein, $(p<0.005)$. Lipoic acid pretreatment increased insulin-stimulated glucose transport following oxidative stress, reaching $84.8 \pm 4.4 \%$ of the control, associated with an increase in reduced glutathione content. Oxidation impaired the $4.89 \pm 0.36$-fold insulin-stimulated increase in glucose transporter 4 content in plasma membrane lawns of control cells. Lipoic acid pretreatment was, however, associated with preserved insulin-induced glucose transporter 4 translocation in cells exposed to oxidation, yielding $80 \%$ of its content in controls. Although tyrosine phosphorylation patterns were not affected by lipoic acid pretreatment, insulin-stimulated protein kinase B/Akt serine 473 phosphorylation and activity were considerably impaired by oxidation but protected by lipoic acid pretreatment. A protective effect was not observed with either troglitazone, its isolated vitamin E moiety, or with vitamin $\mathrm{C}$.

Conclusion/interpretation. This study shows the ability of lipoic acid to provide partial protection against the impaired insulin-stimulated glucose transporter 4 translocation and protein kinase $\mathrm{B} / \mathrm{Akt}$ activation induced by oxidative stress, potentially by its capacity to maintain intracellular redox state. [Diabetologia (1999) 42: 949-957]

Keywords Vitamin C, troglitazone, insulin resistance, vitamin E, GLUT4 translocation.
Oxidative stress has been recently implicated in the pathogenesis of various diseases. Consequently, the

Received: 8 January 1999 and in revised form: 3 March 1999

Corresponding author: N. Bashan, PhD, Department of Clinical Biochemistry, Faculty of Health Sciences, Ben-Gurion University of the Negev, Beer Sheva, Israel, 84105

Abbreviations: LA, Lipoic acid; GLUT4, glucose transporter 4; GLUT1, glucose transporter 1; PKB, protein kinase B/Akt; IR, insulin receptor; TM, total membranes; PM, plasma membranes; PMSF, phenylmethylsulphonyl fluoride; GSH, reduced glutathione. potential therapeutic or preventive effects of antioxidative agents has been raised [1]. Both poorly controlled Type I (insulin-dependent) diabetes mellitus as well as Type II (non-insulin-dependent) diabetes mellitus are characterized by reduced capacity of peripheral tissues (i.e. skeletal muscle and adipose tissue) to respond to the metabolic effects of insulin. The causes and cellular mechanisms responsible for this abnormality are still not fully understood despite intense investigative effort. Several lines of evidence suggest that increased oxidative stress occurs in diabetes and could have a role in the development or deterioration of peripheral insulin resistance. These 
come mainly from clinical studies that correlated oxidative stress variables with the metabolic control of patients $[2,3]$. Other studies reported potential metabolic effects of pharmacological doses of various antioxidative agents given to healthy volunteers or to diabetic subjects [4-6]. These studies provided evidence to suggest an association between oxidative stress and insulin resistance but failed to conclusively establish a cause and effect relation between the two. We used the 3T3-L1 adipocyte cell line model to investigate whether exposing it to oxidative stress results in a reduced ability to respond to insulin $[7,8]$. After exposure to micro molar $\mathrm{H}_{2} \mathrm{O}_{2}$ concentrations, reduced insulin-stimulated glucose transport activity, lipogenesis and glycogenesis were observed, indicating the development of insulin resistance by oxidative stress [7]. Upon investigating the cellular mechanism for this response, further complex changes in the glucose transport machinery induced by oxidative stress were seen. Short-term exposure resulted in interference with the normal insulin signalling network, leading to a reduced ability of the insulin responsive glucose transporter 4 (GLUT4) to be translocated from internal pools to the plasma membrane. When exposure to oxidative stress was extended to $18 \mathrm{~h}$, increased gene expression of the ubiquitous glucose transporter 1 (GLUT1) and down regulation of GLUT4 occurred. The later provided a complementary mechanism for insulin resistance induced by oxidative stress. Interestingly, isolated skeletal muscle preparations as well as L6 myotubes exposed to nitric oxide generating systems were reported by some authors to reduce insulin-stimulated glucose transport activity [9]. This is possibly caused by the intracellular production of the potent oxidant peroxynitrite, further supporting the supposition that oxidative stress may impair insulin action [9].

Recently $\alpha$-lipoic acid (LA) has attracted interest because of its diverse biological actions attributed to its chemical properties $[10,11]$. It is both lipid and water soluble [12], has a potent antioxidative capacity in a wide variety of experimental systems and is a cofactor of key regulatory enzymes including the pyruvate dehydrogenase complex [10]. Recent studies showed that LA exhibits metabolic effects on glucose transport and utilization. In cell culture (L6 myotubes and 3T3-L1 adipocytes), LA at concentrations exceeding $0.5 \mathrm{mmol} / 1$ exerted insulin-like effects, as indicated by the activation of the insulin signalling cascade leading to translocation of glucose transporters $[13,14]$. In animal models of diabetes, treatment with LA resulted in improved peripheral glucose utilization stimulated by insulin $[15,16]$ and prevented diabetes-related reduction in skeletal muscle of the content of GLUT4 [16]. In Type II diabetic patients treatment with LA resulted in improved peripheral glucose utilization assessed by the hyperinsulinaemic clamp technique [4].
Our study was conducted to assess the capacity of LA to protect against the impairment in insulin signalling leading to a reduction in insulin-stimulated glucose transport activity, which is induced by exposure to oxidative stress. These effects were compared with those of vitamin $\mathrm{C}$, a commonly used natural antioxidant, and with troglitazone, a thiazolidinedione insulin sensitizer with a vitamin E moiety in its chemical structure.

\section{Materials and methods}

Chemicals. Tissue culture medium, serum and antibiotic solutions were obtained from Biological Industries (Beit-Haeemek, Israel). Recombinant human insulin was from Novo Nordisk (Bagsvaerd, Denmark). Anti-GLUT4 antibodies were from Chemicon International (Temecula, Calif., USA), anti phospho-specific protein kinase B/Akt (PKB) (Ser473) antibodies were from New England BioLabs Inc. (Beverly, Mass., USA) and anti PKB (C-terminal) antibodies were kindly provided by Dr. R. Seger (Weizmann Institute, Rehovot, Israel). Crosstide and anti-phosphotyrosine antibodies (4G10) were from Upstate Biotechnology (Lake Placid, N. Y., USA). Peroxidase conjugated anti-rabbit IgG and $\gamma-\left[{ }^{32} \mathrm{P}\right]-\mathrm{ATP}$ were from Amersham Life Sciences (Buckingham, UK). We purchased 2-deoxy- $\left[{ }^{3} \mathrm{H}\right]$-glucose from Nuclear Research CentreNegev (Dimona, Israel). Alpha racemic, S(-) and $\mathrm{R}(+)$ lipoic acid were kindly provided by ASTA medica (Frankfurt, Germany). Troglitazone and its isolated vitamin E moiety were kindly provided by Drs. A. R. Saltiel and H.S. Camp (ParkeDavis, Ann Arbor, Mich., USA). All other chemicals were obtained from Sigma Chemical Co (St. Louis, Mo., USA).

Cell culture. We grew 3T3-L1 pre-adipocytes (American Type Culture Collection) to confluence in Dulbeco's modified Eagle's medium (DMEM) containing $25 \mathrm{mmol} / \mathrm{l}$ glucose, as described previously [7]. Cells were induced to differentiate to adipocytes $48 \mathrm{~h}$ after confluence by changing the medium to DMEM supplemented with $10 \%$ fetal calf serum, $5 \mathrm{mg} / \mathrm{ml}$ recombinant human insulin, $0.5 \mathrm{mmol} / 13$-isobutyl-methyl-xanthine and $0.25 \mu \mathrm{mol} / 1$ dexamethasone sodium phosphate for 48-72 h. Cells were used 11-12 days after differentiation induction when exhibiting more than $90 \%$ adipocyte phenotype. Cells were serum deprived for $16 \mathrm{~h}$ by incubation in DMEM supplemented with $0.5 \%$ RIA grade bovine serum albumin (BSA), with or without LA or other pretreatment reagents. Cells were then rinsed three times in PBS and exposed to fresh medium with or without glucose oxidase (type II from $A s$ pergillus niger, $20000 \mathrm{unit} / \mathrm{g}$ solid in non-oxygen saturated conditions, Sigma). The addition of $100 \mathrm{mU} / \mathrm{ml}$ glucose oxidase resulted in medium $\mathrm{H}_{2} \mathrm{O}_{2}$ concentration that achieved a steady state of $27.4 \pm 0.3$ micro molar after $15 \mathrm{~min}$. After 2-h incubation, medium glucose concentrations determined with hexokinase and glucose-6-phosphate dehydrogenase, were $18.2 \pm 2.1$ and $17.4 \pm 1.3 \mathrm{mmol} / \mathrm{l}$ for control and glucose oxidase treated cells, respectively. Insulin stimulation was done after rinsing the cells three times in PBS and further incubation in fresh medium containing $100 \mathrm{nmol} / 1$ insulin for either $7 \mathrm{~min}$, for western blots, or $20 \mathrm{~min}$, for hexose transport determinations.

Hexose transport determinations. 2-Deoxyglucose uptake measurements were done as described previously [7], using $50 \mu \mathrm{mol} / 1$ 2-deoxy- $\left[{ }^{3} \mathrm{H}\right]$ glucose $\left(3.7 \times 10^{4} \mathrm{~Bq} / \mathrm{ml}\right)$ for $10 \mathrm{~min}$. Non-specific uptake (less than $10 \%$ of the total) was determined in the presence of cytochalasin B $(50 \mu \mathrm{mol} / \mathrm{l})$. 
Total membranes (TM) and plasma membrane (PM) lawn preparations. Total membranes were prepared from cells pretreated with or without LA followed by further incubation with or without glucose oxidase, as described previously [7]. Cells $(1 \times 10 \mathrm{~cm}$ plates per condition) were rinsed twice in icecold homogenization buffer [255 mmol/l sucrose, $1 \mathrm{mmol} / \mathrm{l}$ EDTA and $20 \mathrm{mmol} / \mathrm{l} \mathrm{Na-HEPES} \mathrm{(pH} \mathrm{7.4),} 0.2 \mathrm{mmol} / \mathrm{l}$ sodium vanadate, $0.5 \mathrm{mmol} / \mathrm{l}$ phenylmethylsulphonyl fluoride (PMSF), $1 \mu \mathrm{mol} / \mathrm{l}$ pepstatin A, $1 \mu \mathrm{mol} / \mathrm{l}$ leupeptin] and homogenized using a Teflon pestle in a glass homogenizer. The homogenate was centrifuged at $1000 \mathrm{~g}$ for $3 \mathrm{~min}$, after which supernatant was centrifuged at $245000 \mathrm{~g}$ for $90 \mathrm{~min}$ to sediment total membranes. Plasma membranes lawns were prepared as described previously [17]. Cells were washed with PBS and incubated for $1 \mathrm{~min}$ with $0.5 \mathrm{mg} / \mathrm{ml}$ poly-D-lysine followed by 3 washes with hypotonic buffer $(23 \mathrm{mmol} / 1 \mathrm{KCl}, 10 \mathrm{mmol} / \mathrm{l} \mathrm{HEPES}$, $\mathrm{pH} 7.5,1.7 \mathrm{mmol} / \mathrm{l} \mathrm{MgCl}_{2}, 1 \mathrm{mmol} / \mathrm{l}$ EGTA). Cells were then covered with sonication buffer $(3 \times$ hypotonic buffer containing $1 \mathrm{mmol} / 1$ dithiothreitol and $0.1 \mathrm{mmol} / \mathrm{l} \mathrm{PMSF}$ ) and sonicated with a probe membrane disrupter. After sonication, the plasma membrane sheets were washed three times with sonication buffer and used for immunoblotting as described below.

Cell lysates and western blots. Cells were rinsed three times with PBS and incubated in the absence or presence of insulin for $7 \mathrm{~min}$. Lysates for phosphotyrosine immunoblots were prepared in a lysis buffer containing $1 \%$ Triton X-100, $10 \mathrm{mmol} / \mathrm{l}$ sodium pyrophosphate, $50 \mathrm{mmol} / \mathrm{l} \mathrm{NaF}, 10 \%$ glycerol, $80 \mathrm{mmol} / \mathrm{l} \beta$-glycerophosphate, $2 \mathrm{mmol} / \mathrm{l}$ EDTA, $2 \mathrm{mmol} / \mathrm{l}$ EGTA, $2 \mathrm{mmol} / 1$ sodium vanadate, $50 \mathrm{mmol} / 1 \mathrm{HEPES} \mathrm{pH} 7.4$, $1 \mathrm{mmol} / \mathrm{l} \mathrm{PMSF}, 1 \mu \mathrm{mol} / 1$ aprotonin, $1 \mu \mathrm{mol} / 1$ leupeptin and $1 \mu \mathrm{mol} / \mathrm{l}$ pepstatin A. For PKB immunoblots and kinase assay a different lysis buffer was used $(50 \mathrm{mmol} / 1$ TRIS-HCl $\mathrm{pH} 7.5$, $0.1 \%(w / v)$ Triton X-100, $1 \mathrm{mmol} / \mathrm{l}$ EDTA, $1 \mathrm{mmol} / \mathrm{l}$ EGTA, $50 \mathrm{mmol} / \mathrm{l} \mathrm{NaF}, 10 \mathrm{mmol} / \mathrm{l}$ sodium $\beta$-glycerophosphate, $5 \mathrm{mmol} / \mathrm{l}$ sodium pyrophosphate, $1 \mathrm{mmol} / \mathrm{l}$ sodium vanadate, $0.1 \%$ (v/v) 2-mercaptoethanol, $1 \mathrm{mmol} / \mathrm{l} \mathrm{PMSF}, 1$ mol/l aprotonin, $1 \mu \mathrm{mol} / 1$ leupeptin, $1 \mu \mathrm{mol} / 1$ pepstatin A). Lysates were collected, gently shaken for $15 \mathrm{~min}$ at $4{ }^{\circ} \mathrm{C}$, centrifuged $(12000$ $g, 15 \mathrm{~min} 4^{\circ} \mathrm{C}$ ), and the fraction between the pellet and adipose cake collected. Protein concentration was determined using the BCA method (Pierce) for phosphotyrosine immunoblots and the Bio-Rad (Munich, Germany) procedure for PKB. Aliquots of $30-75 \mu \mathrm{g}$ protein (as indicated in the Figure legends) were resolved on $7.5 \%$ or $10 \%$ SDS-PAGE and subjected to western blots, followed by quantitation by video densitometry analysis, as described previously [7].

PKB kinase assay. Anti-C-terminal PKB antibody was added to $400 \mu \mathrm{g}$ cell lysates protein and incubated under constant agitation at $4{ }^{\circ} \mathrm{C}$ overnight. Immunocomplexes were conjugated to protein A sepharose beads $(25 \mu \mathrm{l})$ by incubation for a further $2 \mathrm{~h}$. The activity of PKB kinase was done on immunoprecipitates by a phosphorylation assay using Crosstide (GRPRTSSFAEG) as a substrate [18], following the manufacturer's instructions.

Reduced glutathione (GSH) determinations. At the end of the incubation period cells were washed three times with PBS, scraped and sonicated twice for $20 \mathrm{~s}$ and then centrifuged at $15000 \mathrm{~g}$ for $10 \mathrm{~min}$. Then $1.7 \%$ metaphophsoric acid was added to the supernatant of the sonicated cells $(1: 1, \mathrm{v}: \mathrm{v})$, followed by centrifugation at $5000 \mathrm{~g}$ for $10 \mathrm{~min}$. Reduced glutathione content was measured at $412 \mathrm{~nm}$ in the supernatant by a reaction with 5,5-dithiobis-(2-nitrobenzoic acid) (DTNB, $20 \mathrm{mg}$ DTNB per $100 \mathrm{ml}$ of $1 \%$ sodium citrate solution), as described preciously [19]. Reduced glutathione content was calculated according to a GSH standard curve.
Statistical analysis. Data are expressed as means \pm SEM. Each treatment was compared with the control, and statistical significance between two groups was evaluated using the Student's $t$ test. Significance was set at a $p$ value of 0.05 .

\section{Results}

Lipoic acid pretreatment protects against oxidation-induced reduction in intracellular GSH content. Treatment of fully differentiated 3T3-L1 adipocytes with $100 \mathrm{mU} / \mathrm{ml}$ glucose oxidase for $2 \mathrm{~h}$ resulted in a reduction in intracellular GSH content from $37.4 \pm 3.1$ to $26.4 \pm 4.9 \mathrm{nmol} / \mathrm{mg}$ protein, $p<0.005$, indicating oxidative stress manifested by changed intracellular redox state. To assess the ability of LA pretreatment to protect against the reduction in GSH content following oxidation, cells were incubated for $16 \mathrm{~h}$ with $200 \mu \mathrm{mol} / 1$ racemic LA before further incubation in fresh medium in the absence or presence of glucose oxidase. Reduced glutathione content in LA pretreated cells was $46.1 \pm 5.0$ and $37.9 \pm 2.3 \mathrm{nmol} / \mathrm{mg}$ protein for non-oxidized and for cells treated with glucose oxidase, respectively. These results suggest the ability of LA pretreatment to protect the cells against oxidative stress induced reduction in GSH content.

\section{Lipoic acid pretreatment protects against the reduction} in insulin-stimulated glucose transport activity induced by oxidative stress. The effect of oxidative stress and LA pretreatment on the metabolic response to acute insulin stimulation was studied. In control 3T3-L1 adipocytes, $100 \mathrm{nmol} / 1$ insulin stimulation for $20 \mathrm{~min}$ resulted in an eightfold to eleven fold increase in glucose transport activity. In cells exposed to oxidative stress before insulin stimulation, a twofold increase in basal glucose uptake, associated with a pronounced reduction in insulin-stimulated glucose transport activity, was observed (Fig. 1A, left side). This resulted in a reduction in the calculated net insulin effect above basal activity, from $292.8 \pm 18.6$ to $108.8 \pm 28.0 \mathrm{pmol} \cdot \mathrm{mg}^{-1} \cdot$ protein $^{-1}$. $\min ^{-1}(p<0.001)$. The potential of LA pretreatment to prevent the impairment in insulin-stimulated glucose transport induced by oxidative stress was evaluated. Basal glucose transport was not affected by $200 \mu \mathrm{mol} / \mathrm{l}$ racemic LA pretreatment either in cells treated with glucose oxidase or in untreated cells. It provided, however, a significant $(p<0.03)$, though not complete, protection against the reduction induced by glucose oxidase in insulin-stimulated glucose transport activity (Fig.1A, right side), reaching $86.3 \pm 4.3 \%$ of the activity observed with LA pretreated, non-oxidized cells. To further characterize the protective effect of LA, cells were incubated with increasing concentrations of racemic LA for $16 \mathrm{~h}$ before exposure to glucose oxidase and assess- 
A.

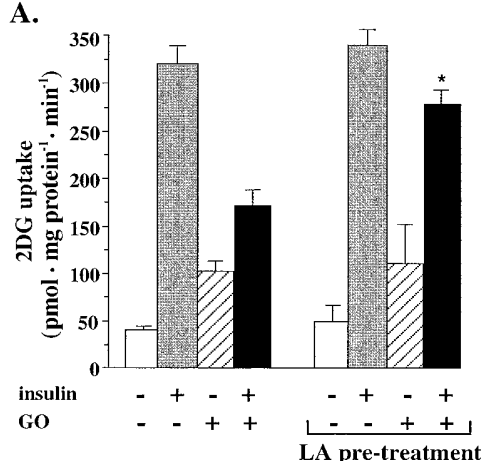

C.

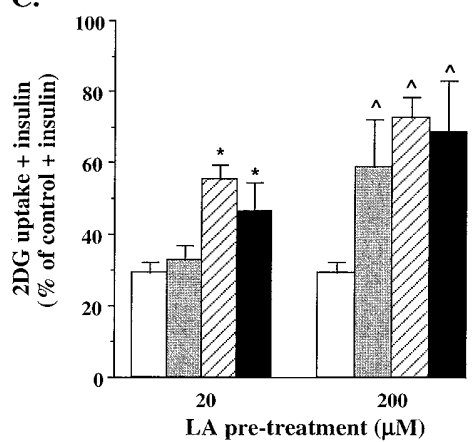

B.

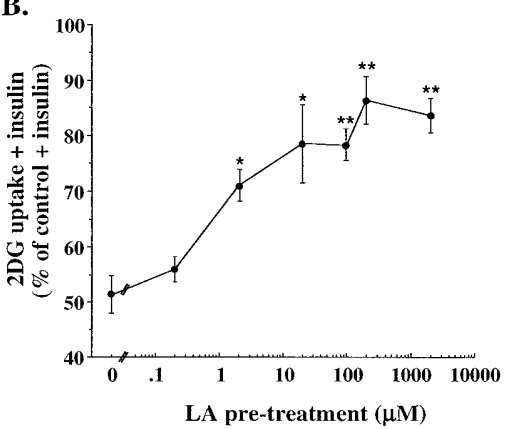

D.

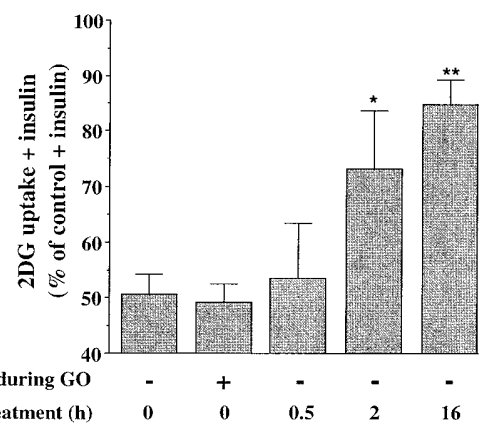

Fig.1A-D. Treatment with lipoic acid prevents the impairment in insulin-stimulated glucose transport induced by oxidative stress. A Fully differentiated 3T3-L1 adipocytes were incubated for $16 \mathrm{~h}$ in serum-deprived medium with or without $200 \mu \mathrm{mol} / 1$ racemic LA. Cells were then rinsed with PBS and incubated for $2 \mathrm{~h}$ more in medium without or with $100 \mathrm{mU} / \mathrm{ml}$ glucose oxidase $(\mathrm{GO})$. Subsequently, cells were rinsed again and exposed for $20 \mathrm{~min}$ to medium without or with $100 \mathrm{nmol} / \mathrm{l}$ insulin, after which glucose uptake was measured as described in Materials and methods. Results are presented as means \pm SEM of six independent experiments. ${ }^{*} p<0.003$ as compared with insulin-stimulated GO-treated cells and $p<0.01$ compared with LA pretreated, non-oxidized cells in the presence of insulin. B Cells were treated with different concentrations of racemic LA before exposure to glucose oxidase, as described in $\mathbf{A}$ and insulin-stimulated glucose transport activity was measured. Results (in \% of the activity measured in insulin-stimulated, non-oxidized cells), are the means \pm SEM of three independent experiments. ${ }^{*} p<0.05$ and $* * p<0.01 \mathrm{com}-$ pared with insulin-stimulated GO-treated cells. C Cells were treated without (-LA) or with either 20 or $200 \mu \mathrm{mol} / 1$ of the $\mathrm{R}(+)$ LA isomer, the S(-) LA isomer or the racemic LA for $16 \mathrm{~h}$ before exposure to glucose oxidase and insulin-stimulated glucose transport activity was measured, as described in $\mathbf{A}$. Results are the means \pm SEM of three independent experiments done in duplicate. $* p<0.05$ and $\wedge p<0.01$ compared with -LA. D Cells were treated with $200 \mu \mathrm{mol} / 1$ racemic LA only during glucose oxidase treatment or at $0.5,2$ or $16 \mathrm{~h}$ before exposure to glucose oxidase, after which insulin-stimulated glucose transport activity was measured. Values are means \pm SEM of two independent experiments done in duplicate. $* p<0.05$ and $* * p<0.01$ compared with insulin-stimulated GO-treated cells. $\square,-\mathrm{LA} ; \square, \mathrm{R}(+) \mathrm{LA} ; \mathbb{Z}, \mathrm{S}(-) \mathrm{LA} ; \mathbf{\square}$, racemic LA ment of insulin-stimulated glucose transport activity. Figure 1B shows a dose-response curve in which a protective effect of LA can be observed with $2 \mu \mathrm{mol} / \mathrm{l}$ LA reaching $84.8 \pm 4.4 \%$ of the activity observed in control cells when $200 \mu \mathrm{mol} / \mathrm{l} \mathrm{LA}$ were used. A similar protective effect to those observed with $200 \mu \mathrm{mol} / \mathrm{l} \mathrm{LA}$ was provided by $2 \mathrm{mmol} / \mathrm{l}$ but that of $2 \mathrm{mmol} / \mathrm{l} \mathrm{LA}$ was associated with a fourfold increase in basal glucose transport (not shown). The protective potency of the two stereo isomers of LA, R( + )LA and S(-)-LA was compared with that of the racemic mixture. In this particular set of experiments glucose oxidase treatment resulted in a $70 \%$ reduction in insulin-stimulated glucose transport activity. Figure $1 \mathrm{C}$ shows that with a $20 \mu \mathrm{mol} / \mathrm{l}$ concentration, the protective capacity of the S-LA isomer was significantly $(p<0.05)$ superior to that of the R-LA, whereas the racemic mixture had an intermediate protective potential. These differences could not, however, be shown when a higher concentration of each reagent was used. Hence, as $200 \mu \mathrm{mol} / \mathrm{l}$ racemic LA provided the maximum protective effect (Fig.1B) without directly activating basal glucose transport (Fig.1A), subsequent experiments were done using this concentration of racemic LA. Figure $1 \mathrm{D}$ shows that the presence of LA alone during glucose oxidase treatment was not associated with any improved response to insulin compared with cells exposed to glucose oxidase in the absence of LA. Moreover, a protective effect could be observed only following 2-h pretreatment but not after $30 \mathrm{~min}$. These data may suggest that in this system LA effect is dependent on processes that require its uptake, metabolism or interaction with intracellular targets. 
Total membranes

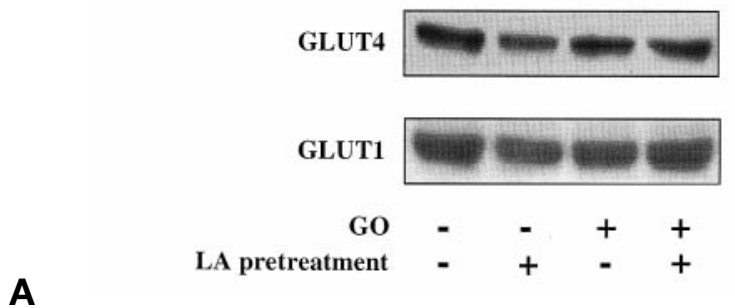

PM lawn GLUT4
- LA
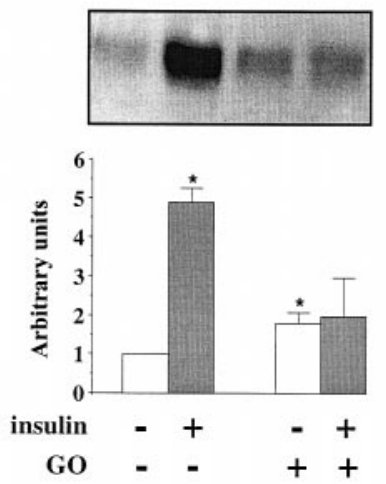

LA pretreatment
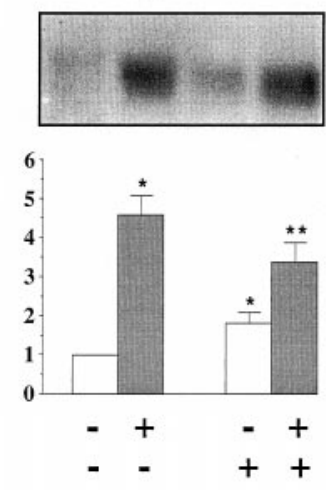

B

Fig. 2 A, B. Pretreatment with lipoic acid prevents the impaired insulin-stimulated GLUT4 translocation induced by oxidative stress. A 3T3-L1 adipocytes were incubated with or without $200 \mu \mathrm{mol} / 1$ racemic LA for $16 \mathrm{~h}$ before further incubation with or without glucose oxidase, as described in the legend for Fig. 1A. Total membrane preparations were prepared as described in Materials and methods. Total membrane protein $(30 \mu \mathrm{g})$ was separated on SDS-PAGE, followed by immunoblot analysis using either anti-GLUT4 or anti-GLUT1 antibodies. Shown is a blot representing similar results from three independent experiments. B Cells were treated as described in the legend for Fig. 1A, after which plasma membrane lawns were prepared as described in Materials and methods. Protein samples $(30 \mu \mathrm{g})$ were separated on SDS-PAGE, followed by immunoblot analysis using anti-GLUT4 antibodies. Shown are blots representing three independent experiments. The results of video densitometry analysis, in which a value of 1 unit was set to represent GLUT4 content in non-oxidized cells in the absence of insulin, are shown in the lower panel. ${ }^{*} p<0.02$ compared with non-oxidized cells in the absence of insulin. $* * p=0.014$ compared with LA pretreated oxidized cells in the absence of insulin

Lipoic acid pretreatment protects the capacity of insulin to induce GLUT4 translocation to the plasma membrane after oxidative stress. We addressed the possibility that LA affected insulin-stimulated glucose transport by changing the content or function of glucose transporters. Figure $2 \mathrm{~A}$ is a western blot analysis of total membranes GLUT4 and GLUT1 content, representing three independent experiments. Based on densitometric analysis (data not shown), 16-h exposure to LA followed by 2-h incubation with glucose oxidase had no effect on total mem- brane GLUT4 or on GLUT1 content. The dominant glucose transporter responsible for insulin-stimulated glucose transport in 3T3-L1 adipocytes is GLUT4. Thus, its translocation to the plasma membrane (PM) in response to insulin stimulation was assessed. Plasma membrane lawns were prepared as described [17], followed by western blot analysis. As depicted in Figure 2B (left side), insulin induced a $4.89 \pm 0.36$ fold increase in PM lawn GLUT4 content in control cells. Although glucose oxidase treatment induced a $1.8 \pm 0.26$-fold increase in PM GLUT4 content, rapid insulin stimulation of these cells did not produce any further increase. Lipoic acid pretreatment did not affect the ability of insulin to increase PM GLUT4 content in non-oxidized cells (Fig. 2B, right side) but provided a protective effect against the impaired insulinstimulated GLUT4 translocation induced by oxidative stress.

The effect of LA pretreatment on insulin-stimulated $P K B$ Serine 473 phosphorylation and activity and on the protein tyrosine phosphorylation pattern after oxidative stress. Protein kinase B/Akt has been recognized as a serine kinase that is activated down stream of PI 3-kinase after insulin stimulation [20-22]. Recent studies indicate that it could be involved in insulin-stimulated GLUT4 translocation [23-26]. To assess whether oxidative stress impairs insulin-stimulated PKB activation and whether the protective effect of LA is related to a preserved ability of insulin to activate $\mathrm{PKB}$, phospho-specific PKB immunoblots as well as PKB activity were assessed. Insulin stimulation considerably increased the amount of phosphoserine 473 specific PKB (Fig. 3A), a response greatly reduced by glucose oxidase treatment. In LA pretreated cells, a non-significant reduction in PKB content assessed by antibodies directed against the C-terminal of PKB was observed (Fig. 3A, lower blot). Yet, LA treatment before exposure to glucose oxidase resulted in partial protection against the reduction in insulin-stimulated PKB Ser 473 phosphorylation compared with LA-treated control cells. The significance of this result was further evaluated by measurements of PKB activity in immunoprecipitates obtained using the anti-PKB C-terminal antibody. The activity of PKB largely correlated with the results obtained with anti-phosphoserine PKB immunoblot (Fig.3B), further showing that LA prevents impairment induced by oxidative stress in PKB activation by insulin.

To determine whether these effects of LA are associated with changes in the first steps of the insulin signalling cascade, the protein tyrosine phosphorylation pattern was assessed in total cell lysates. Insulininduced tyrosine phosphorylation of $95 \mathrm{kDa}$ and 185 $\mathrm{kDa}$ bands which correspond to the $\beta$ subunit of the insulin receptor and to insulin receptor substrates (IRS), respectively. Neither oxidative stress nor LA 
A.

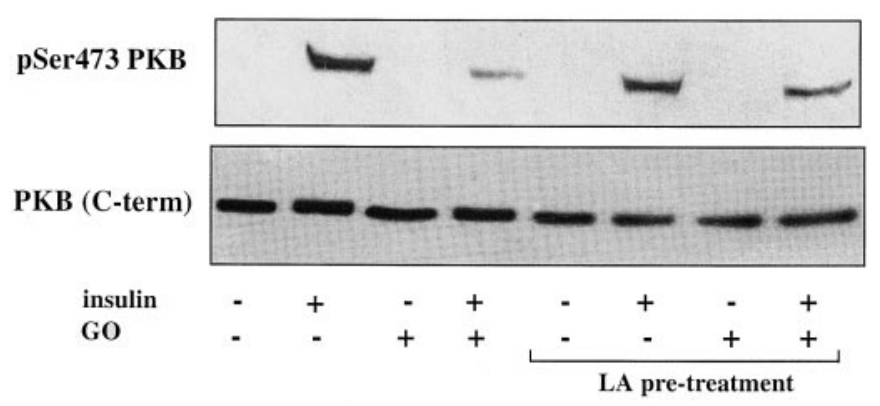

B.

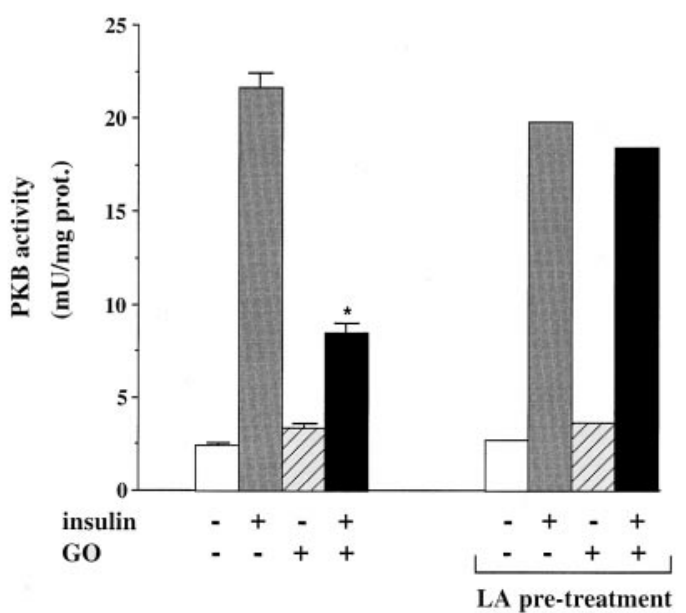

Fig. 3 A, B. Pretreatment with lipoic acid prevents the impairment induced by oxidative stress in insulin-stimulated PKB Ser473 phosphorylation and activity. Cells were treated as described in the legend for Fig. 1A and cell lysates were prepared in PKB lysis buffer as described in Materials and methods. A Total cell lysates $(50 \mu \mathrm{g})$ were separated on SDS-PAGE, followed by immunoblot analysis using either a phospho-Serine 473 specific anti-PKB antibody or an anti-PKB antibody directed against the $\mathrm{C}$-terminal tail of $\mathrm{PKB}$. Shown are blots representative of three independent experiments. B Total cell lysates $(400 \mu \mathrm{g})$ were subjected to immunoprecipitation using the anti-C-terminal PKB antibody, after which PKB activity was measured as described in Materials and methods. Shown are the results expressed as milli-unit enzyme activity per mg protein. In the absence of LA pretreatment, the results are average \pm SEM of four independent experiments. For LA pretreated cells, data are the mean of two independent experiments. ${ }^{*} p<0.001$ compared with insulin-treated, non-oxidized cells

treatment changed basal or insulin-induced protein tyrosine phosphorylation patterns (Fig. 4). This result indicates that $200 \mu \mathrm{mol} / \mathrm{l} \mathrm{LA}$ pretreatment did not activate the first steps of the insulin signal, but rather prevented the impairment in insulin-stimulated PKB activity by directly antagonizing the effects of oxidation.

The effect of LA, troglitazone, its isolated vitamin $E$ moiety and vitamin $C$ pretreatment on glucose trans-

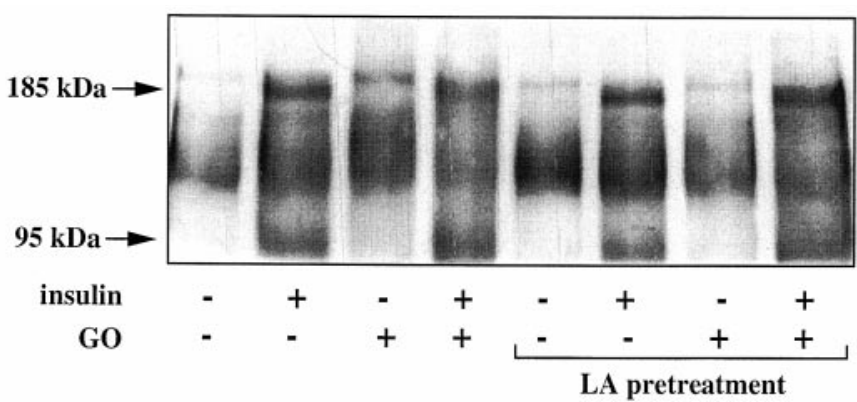

Fig. 4. Effect of glucose oxidase and LA pretreatment on basal- and insulin-stimulated tyrosine phosphorylation. Cells were treated as described in the legend for Fig. 1A, and cell lysates were prepared as described in Materials and methods. Total cell lysates $(75 \mu \mathrm{g})$ were separated on SDS-PAGE, followed by immunoblot analysis using anti-phosphotyrosine antibody (4G10). Arrows indicate molecular weights of 185 $\mathrm{kDa}$, which corresponds to IRSs, and $95 \mathrm{kDa}$, which corresponds to the $\beta$ sub-unit of the insulin receptor. Shown is a blot representing five independent experiments

port activity after oxidative stress. The thiazolidinedione insulin sensitizer troglitazone is composed of a vitamin $\mathrm{E}$ moiety conjugated to a dione moiety. The antioxidative capacity of this compound has been reported $[27,28]$ and may have a role in its insulin sensitizing action. Vitamin $\mathrm{C}$ is a clinically used antioxidant that is water soluble and has potential effects on peripheral glucose utilization $[6,29]$. Thus, the potential protective effects of troglitazone, its isolated vitamin $\mathrm{E}$ moiety and of vitamin $\mathrm{C}$ against insulin resistance induced by oxidative stress were evaluated. Neither $5 \mu \mathrm{mol} / \mathrm{l}$ troglitazone, $5 \mu \mathrm{mol} / \mathrm{l}$ of its isolated vitamin $E$ moiety nor $300 \mu \mathrm{mol} / 1$ vitamin $C$ had a significant protective effect against impairment induced by oxidative stress in insulin-stimulated glucose transport as observed with LA. This was so both in the absolute values of 2DG uptake activity (Fig. 5A) and in the calculated net insulin effect above basal (Fig. 5B). Higher concentrations (up to $100 \mu \mathrm{mol} / \mathrm{l}$ ) of either troglitazone or its vitamin E moiety failed to show any significant effect on insulin-stimulated glucose transport after oxidative stress (data not shown). These data show that in this system LA, potentially through its characteristic bio-chemical properties, protects against the effects of oxidative stress on insulin action.

\section{Discussion}

In this study we show that LA protects against the impairment in insulin-stimulated PKB activation and GLUT4 translocation induced by directly exposing 3T3-L1 adipocytes to oxidative stress. This effect of LA was associated with protection against oxidationinduced reduction in cellular GSH content, confirming its antioxidant activity. 
A.

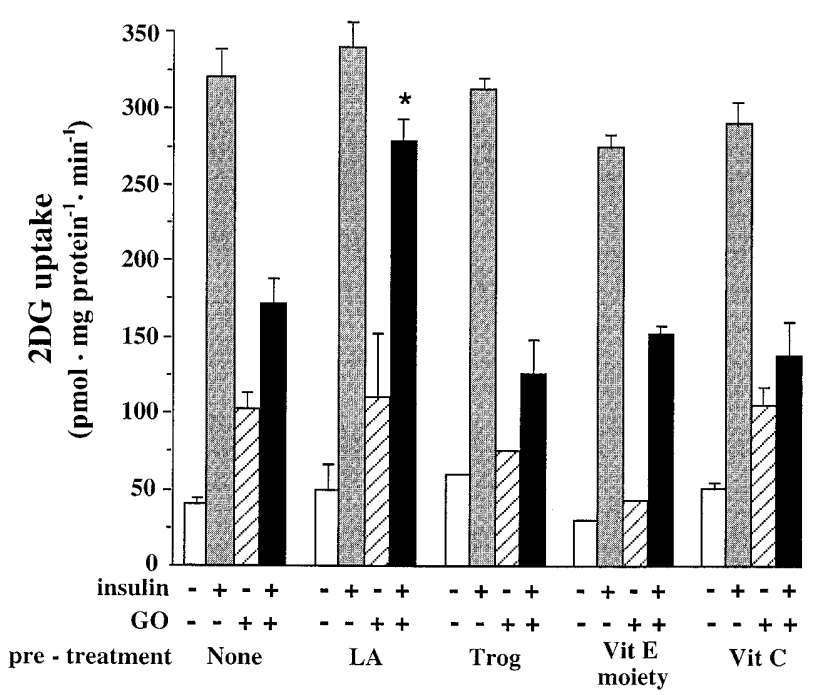

B.

\begin{tabular}{|lcc|}
\hline & \multicolumn{2}{c|}{$\begin{array}{c}\text { net insulin effect on glucose transport } \\
\text { (pmole / mg prot. / min. })\end{array}$} \\
Treatement & - GO & + GO \\
\hline None & $292.8 \pm 18.6$ & $108.8 \pm 28.0$ \\
\hline LA $(200 \mu \mathrm{M})$ & $296.0 \pm 25.0$ & $211.6 \pm 19.6 *$ \\
\hline Troglitazone $(5 \mu \mathrm{M})$ & $300.0 \pm 15.0$ & $72.7 \pm 6.0$ \\
\hline Vit E moiety $(5 \mu \mathrm{M})$ & $247.0 \pm 11.3$ & $109.0 \pm 5.0$ \\
\hline Vit C $(300 \mu \mathrm{M})$ & $318.0 \pm 43.6$ & $81.6 \pm 14.9$ \\
\hline
\end{tabular}

Fig. 5 A, B. Effect of pretreatment with LA, troglitazone, the isolated vitamin $\mathrm{E}$ moiety of troglitazone and of vitamin $\mathrm{C}$ on the effect of glucose oxidase on insulin responsiveness. A Cells were treated with either racemic LA $(200 \mu \mathrm{mol} / \mathrm{l})$, troglitazone $(5 \mu \mathrm{mol} / \mathrm{l})($ Trog$)$, the isolated vitamin E moiety of troglitazone $(5 \mu \mathrm{mol} / 1)$, or with vitamin C (ascorbic acid) $(300 \mu \mathrm{mol} / 1)$ before exposure to glucose oxidase, as described above. 2DG uptake activity was determined as described in Materials and methods. Each value is the means \pm SEM of two to five independent experiments. ${ }^{*} p<0.01$ compared with insulin-stimulated glucose transport in oxidized cells without pretreatment. B Net insulin effect was calculated in each experiment as the insulin-stimulated 2DG uptake activity minus its value without insulin stimulation. The table presents means \pm SEM values from two to five independent experiments. ${ }^{*} p<0.01$ compared with the net insulin effect in glucose oxidase-treated cells with no pretreatment

Lipoic acid has been shown to exert beneficial effects in diabetes-related conditions in which oxidative stress was suggested to have a pathogenic role. The ALADIN study found a beneficial clinical effect of LA in the treatment of diabetic polyneuropathy [30]. In accordance with this, using animal models LA has been shown to prevent the diabetes-related reduction in peripheral nerve conduction velocity and endoneural blood flow $[31,32]$. In addition, the occurrence of neural tube defects in embryos of diabetic rats could be greatly reduced by LA treatment [33]. Recently, several lines of evidence suggest that oxidative stress may have a role in the pathogenesis of peripheral insulin resistance. In both STZ diabetic rats as well as in Fatty Zucker rats, LA treatment improved skeletal muscle glucose utilization $[15,16]$. These findings were supported by a report suggesting improved peripheral glucose utilization in diabetic patients after treatment with LA [4]. Whether LA exerted its pharmacological effects by means of its antioxidative capacity could not, however, be explained by these studies. In our study LA pretreatment showed protection against both oxidative stress-induced insulin resistance and GSH depletion. This suggests a possible association between the two, supporting the notion that oxidative stress has a role in the development of insulin resistance.

The protective capacity of LA against reduction in GSH cellular content has been suggested as an explanation for its biological effects. For example, C6 glial cells were protected from cell death induced by oxidative stress produced by glutamate when pretreated with $100 \mu \mathrm{mol} / 1 \mathrm{LA}$ [34]. In 3T3-L1 adipocytes, glucose oxidase treatment resulted in $30 \%$ reduction in GSH content. This degree of GSH depletion did not cause cellular death but may still interfere with reduced sulphydryl sensitive steps along the insulin signal resulting in impaired GLUT4 translocation. Various proteins along the insulin signalling cascade, as well as proteins participating in the cellular trafficking and fusion processes, have been suggested to be reduced sulphydryl sensitive [35-39]. The maintenance of normal cellular GSH content in oxidized 3T3-L1 adipocytes by LA may thus protect potential reduced sulphydryl dependent proteins participating in the insulin signalling cascade, resulting in improved insulin action following oxidative stress.

Reduced glutathione maintaining capacity has been suggested as the primary mechanism for LA action at low doses [34, 40]. In addition, doses exceeding $500 \mu \mathrm{mol} / 1$ may represent modes of action independent of the pro-GSH properties, such as the stimulation of specific proteins synthesis or direct interaction with signal transduction effectors [34, 41]. In agreement with this, in 3T3-L1 adipocytes LA at millimolar concentrations increased glucose transport by direct activation of IRS-1 tyrosine phosphorylation, activation of PI 3-kinase and PKB activities [13, 14]. In our study we observed, however, that LA concentrations of up to $200 \mu \mathrm{mol} / 1$ were not associated with either activation of basal glucose transport activity (Fig. 1A), stimulation of IRS or insulin receptor tyrosine phosphorylation (Fig. 4), or with basal PKB activation (Fig. 3).

Previous studies aimed at assessing the metabolic effects of LA in both in-vitro and in-vivo models have shown the $\mathrm{R}(+)$ isomer as being more potent 
than the $\mathrm{S}(-)$ isomer $[42,43]$. This stereo isomer has been reported to have a higher affinity to both the E2 component of enzymatic complexes such as pyruvate dehydrogenase as well as to dihydrolipoamide dehydrogenase, which converts lipoic acid to dihydrolipoic acid [44, 45]. Thus, the effects of R-LA on glucose transport and metabolism can be attributed to its potential direct effect on key metabolic enzymes or to the antioxidant properties of dihydrolipoic acid or both. In this study we observed a slightly increased biological efficacy of the $S$ compared with the $\mathrm{R}$ isomer with $20 \mu \mathrm{mol} / \mathrm{l}$ pretreatment but not with higher concentrations (Fig. 1C). This isomer of LA exerts a slightly increased affinity for glutathione reductase [46], which has a key role in glutathione recycling and maintenance of cellular GSH concentrations. The protective effects of LA treatment depended on a preincubation period of at least $2 \mathrm{~h}$ (Fig.1D) and were associated with prevention of oxidation-induced GSH depletion. Thus it appears that at a $20 \mu \mathrm{mol} / 1$ racemic LA pretreatment, its capacity to preserve normal intracellular GSH concentration (potentially by increasing GSH recycling efficiency), is its major mode of action. This could explain the higher potency of the $\mathrm{S}(-)$ isomer at this concentration. With $200 \mu \mathrm{mol} / \mathrm{l}$ racemic LA pretreatment, the antioxidant properties of the dihydrolipoic acid metabolite, derived primarily from the $\mathrm{R}(+)$ isomer, may increasingly contribute to its overall biological potency. Additional modes of action of LA may potentially include changes in the expression or function of endogenous antioxidant enzymes such as superoxide dismutase or catalase.

In the experimental system used in this study, LA was found to be interesting in its ability to protect against oxidative stress-induced insulin resistance compared with vitamin $\mathrm{C}$ or with troglitazone and its isolated vitamin $\mathrm{E}$ moiety (Fig.5). The bio-activity of LA was attributed both to its ability to directly react with various reactive oxygen species, as well as to its ability to interfere with oxidation processes in the lipid and in the aqueous cellular compartments [11, 12]. As discussed above, the second possibility is more likely in this system in light of the requirement of at least 2-h incubation with LA before exposure to glucose oxidase, as well as the lack of effect of LA when present only during glucose oxidase treatment (Fig. 1D). In that sense, LA is perhaps superior to vitamin $\mathrm{C}$, which is a water-soluble antioxidant, and to the vitamin E moiety of troglitazone, which is lipid soluble. In accordance with this, GSH concentrations after oxidation were identical to non-oxidized control cells when cells were pretreated with LA but not with vitamin $\mathrm{C}$ (not shown).

The exact oxidation sensitive step within the insulin signal, which is protected by LA pretreatment, cannot be directly determined by this study. Recently, we observed that oxidative stress may interfere with the insulin-induced translocation of PI 3-kinase to the low-density microsomes and its activation in this fraction [47]. This was associated with impaired PKB phosphorylation and activation by insulin. In this study the effect of oxidative stress and of LA pretreatment on insulin-stimulated PKB activity (Fig. 3) closely correlated with their effects on glucose transport activity and on GLUT4 translocation (Figs. 1A and $2 \mathrm{~B}$, respectively). These are consistent with the notion that PKB activation has a role in the induction of GLUT4 translocation by insulin [22, 23, 25, 26] and thus in the protective mechanism against oxidative stress exerted by LA pretreatment. Whether the insulin stimulation of PKB activity is in itself a reduced sulphydryl dependent process or rather reflects upstream oxidative sensitive steps, such as the translocation and activation of PI 3-kinase in the low density microsomes, remains to be evaluated. From the above it is apparent that LA pretreatment has the ability to preserve PKB activation and thereby protects against the induction of insulin resistance.

Impaired insulin-stimulated GLUT4 translocation is a well documented finding in skeletal muscle and adipose tissue of Type II diabetic and insulin resistant subjects [48]. The aetiology and the cellular mechanisms for this abnormality are not fully understood. Raised plasma concentrations of non-esterified fatty acids, TNF- $\alpha$, hyperinsulinaemia, as well as oxidative stress have been suggested to have a role in the pathogenesis of peripheral insulin resistance [49-51]. The findings of this study suggest that impaired insulin stimulation of GLUT4 translocation may be partly prevented by maintaining intracellular redox state using the antioxidant LA.

Acknowledgements. This work was supported by grants from the Israeli Ministry of Health and from the Israeli Academy of Sciences (both to N. Bashan and A. Rudich) and by the American Physician Fellowship Edward H. Kass Fund Award (to A. Rudich).

\section{References}

1. Balz F (1994) Natural antioxidants in human health and disease. Academic Press, San Diego, Ca

2. Paolisso G, D'Amore A, Di Maro G et al. (1993) Evidence for a relationship between free radicals and insulin action in the elderly. Metabolism 42: 659-663

3. Nourooz-Zadeh J, Rahimi A, Tajaddini-Sarmadi J et al. (1997) Relationship between plasma measures of oxidative stress and metabolic control in NIDDM. Diabetologia 40: 647-653

4. Jacob S, Henriksen EJ, Schiemann AL et al. (1995) Enhancement of glucose disposal in patients with type 2 diabetes by alpha-lipoic acid. Arzneimittelforschung 45: 872-874

5. Caballero B (1993) Vitamin E improves the action of insulin. Nutr Rev 51: 339-340

6. Paolisso G, D’Amore A, Balbi V et al. (1994) Plasma vitamin C affects glucose homeostasis in healthy subjects and in non-insulin-dependent diabetics. Am J Physiol 266: E261-E268

7. Rudich A, Kozlovsky N, Potashnik R, Bahan N (1997) Oxidant stress reduces insulin responsiveness in 3T3-L1 adipocytes. Am J Physiol 272: E935-E940 
8. Rudich A, Tirosh A, Potashnik R, Hemi R, Kanety H, Bashan N (1998) Prolonged oxidative stress impairs insulin-induced GLUT4 translocation in 3T3-L1 adipocytes. Diabetes 47: 1562-1569

9. Kapur S, Bedard S, Marcotte B, Cote CH, Marette A (1997) Expression of nitric oxide synthase in skeletal muscle: a novel role for nitric oxide as a modulator of insulin action. Diabetes 46: $1691-1700$

10. Fuchs J, Packer L, Zimmer G (1997) Lipoic acid in Health and Disease. Marcel Dekker, New York Basel Hong Kong

11. Packer L, Witt EH, Tritschler HJ (1995) alpha-Lipoic acid as a biological antioxidant. Free Radic Biol Med 19: 227-50

12. Kagan VE, Shvedova A, Serbinova E et al. (1992) Dihydrolipoic acid - a universal antioxidant both in the membrane and in the aqueous phase. Reduction of peroxyl, ascorbyl and chromanoxyl radicals. Biochem Pharmacol 44: 1637-1649

13. Estrada DE, Ewart HS, Tsakiridis Tet al. (1996) Stimulation of glucose uptake by the natural coenzyme alpha-lipoic acid/thioctic acid: participation of elements of the insulin signalling pathway. Diabetes 45: $1798-1804$

14. Yaworsky K, Somwar R, Ramlal Tet al. (1998) In vivo activation of the insulin receptor tyrosine kinase and activation of the insulin signalling pathways by a-lipoic acid results in stimulation of glucose uptake in 3T3-L1 adipocytes [Abstract]. Diabetes 47:A277

15. Jacob S, Streeper RS, Fogt DL et al. (1996) The antioxidant alphalipoic acid enhances insulin-stimulated glucose metabolism in insulin-resistant rat skeletal muscle. Diabetes 45: 1024-1029

16. Khamaisi M, Potashnik R, Tirosh A et al. (1997) Lipoic acid reduces glycemia and increases muscle GLUT4 content in streptozotocin-diabetes rats. Metabolism 46: 763-768

17. Chen D, Elmendorf JS, Olson AL, Li X, Earp HS, Pessin JE (1997) Osmotic shock stimulates GLUT4 translocation in 3T3-L1 adipocytes by a novel kinase pathway. J Biol Chem 272: 27401-27410

18. Cross DA, Alessi DR, Cohen P, Andjelkovich M, Hemmings BA (1995) Inhibition of glycogen synthase kinase-3 by insulin mediated by protein kinase B. Nature 378: 785-789

19. Beutler E (1975) Reduced glutathione. In: Red cell metabolism. Grune \& Stratton, New York San Francisco London, pp 112-114

20. Burgering BM, Coffer PJ (1995) Protein kinase B (c-Akt) in phosphatidylinositol-3-OH kinase signal transduction. Nature 376: 599-602

21. Alessi DR, Cohen P (1998) Mechanism of activation and function of protein kinase B. Curr Opin Genet Dev 8: 55-62

22. Kohn AD, Kovacina KS, Roth RA (1995) Insulin stimulates the kinase activity of RAC-PK, a pleckstrin homology domain containing ser/thr kinase. EMBO J 14: 4288-4295

23. Kohn AD, Summers SA, Birnbaum MJ, Roth RA (1996) Expression of a constitutively active Akt Ser/Thr kinase in 3T3-L1 adipocytes stimulates glucose uptake and glucose transporter 4 translocation. J Biol Chem 271: 31372-31378

24. Tanti JF, Grillo S, Gremeaux T, Coffer PJ, Van Obberghen E, Le Marchand Brustel Y (1997) Potential role of protein kinase B in glucose transporter 4 translocation in adipocytes. Endocrinology 138: 2005-2010

25. Cong LN, Chen H, Li Y et al. (1997) Physiological role of Akt in insulin-stimulated translocation of GLUT4 in transfected rat adipose cells. Mol Endocrinol 11: 1881-1890

26. Hajduch E, Alessi DR, Hemmings BA, Hundal HS (1998) Constitutive activation of protein kinase $\mathrm{Ba}$ by membrane targeting promotes glucose and system A amino acid transport, protein synthesis, and inactivation of glycogen synthase kinase 3 in L6 muscle cells. Diabetes 47: 1006-1013

27. Cominacini L, Garbin U, Pastorino AM et al. (1997) Effects of troglitazone on in vitro oxidation of LDL and HDL induced by copper ions and endothelial cells. Diabetologia 40: 165-172

28. Noguchi N, Sakai H, Kato Y et al. (1996) Inhibition of oxidation of low density lipoprotein by troglitazone. Atherosclerosis 123: 227-234

29. Paolisso G, Balbi V, Volpe C et al. (1995) Metabolic benefits deriving from chronic vitamin $\mathrm{C}$ supplementation in aged non-insulin dependent diabetics. J Am Coll Nutr 14: 387-392
30. Ziegler D, Hanefeld M, Ruhnau KJ et al. (1995) Treatment of symptomatic diabetic peripheral neuropathy with the anti-oxidant alpha-lipoic acid. A 3-week multicentre randomized controlled trial (ALADIN Study). Diabetologia 38: 1425-1433

31. Nagamatsu M, Nickander KK, Schmelzer JD et al. (1995) Lipoic acid improves nerve blood flow, reduces oxidative stress, and improves distal nerve conduction in experimental diabetic neuropathy. Diabetes Care 18: 1160-1167

32. Cameron NE, Cotter MA, Horrobin DH, Tritschler HJ (1998) Effects of alpha-lipoic acid on neurovascular function in diabetic rats: interaction with essential fatty acids. Diabetologia 41: 390-399

33. Wiznitzer A, Ayalon N, Hershkovitz R et al. (1999) Lipoic acid prevention of neural tube defects in offspring of rats with streptozotocin-induced diabetes. Am J Obstet Gynecol 180: 188-193

34. Han D, Sen CK, Roy S, Kobayashi MS, Tritschler HJ, Packer L (1997) Protection against glutamate-induced cytotoxicity in C6 glial cells by thiol antioxidants. Am J Physiol 273:R1771-R1778

35. Begum N (1994) Phenyarsine oxide inhibits insulin-stimulated protein phosphatase 1 activity and GLUT4 translocation. Am J Physiol 267:E14-E23

36. Holman GD, Kasuga M (1997) From receptor to transporter: insulin signalling to glucose transport. Diabetologia 40: 991-1003

37. Rothman JE, Warren G (1994) Implications of the SNARE hypothesis for intracellular membrane topology and dynamics. Curr Biol 4: 220-233

38. Schnitzer JE, Allard J, Oh P (1995) NEM inhibits transcytosis, endocytosis, and capillary permeability: implication of caveolae fusion in endothelia. Am J Physiol 268:H48-H55

39. Rea S, James DE (1997) Moving GLUT4: the biogenesis and trafficking of GLUT4 storage vesicles. Diabetes 46: 1667-1677

40. Han D, Handelman G, Marcocci L et al. (1997) Lipoic acid increases de novo synthesis of cellular glutathione by improving cystine utilization. Biofactors 6: 321-338

41. Sen CK, Packer L (1996) Antioxidant and redox regulation of gene transcription. FASEB J 10: 709-720

42. Klip A, Volchuk A, Ramlal T, Ackerley C, Mitsumoto Y (1994) Glucose transporters of muscle cells in culture: Developmental regulation and modulation by lipoic acid, an antihyperglycemic agent. In: Draznin B, LeRoith D (eds) Molecular Biology of Diabetes. Humana Press Inc., Totowa, NJ, pp 511-528

43. Streeper RS, Henriksen EJ, Jacob S, Hokama JY, Fogt DL, Tritschler HJ (1997) Differential effects of lipoic acid stereoisomers on glucose metabolism in insulin-resistant skeletal muscle. Am J Physiol 273:E185-E191

44. Arscott LD, Williams CH Jr (1994) R- and S-dihydrolipoic acid derivatives as substrates of lipoamide dehydrogenase. In: Yagi K (ed) Flavins and flavoproteins 1993, proceedings of the eleventh international symposium. de Gruyter, Berlin New York, pp 527-530

45. Podda M, Traber MG, Packer L (1997) $\alpha$-Lipoate: Antioxidant properties and effects on skin. In: Fuchs J, Packer L, Zimmer G (eds) Lipoic acid in health and disease. Marcel Dekker, New York, pp 163-180

46. Pick U, Haramaki N, Constantinescu A, Handelman GJ, Tritschler HJ, Packer L (1995) Glutathione reductase and lipoamide dehydrogenase have opposite stereospecificities for alpha-lipoic acid enantiomers. Biochem Biophys Res Commun 206: 724-730

47. Tirosh A, Potashnik R, Bashan N, Rudich A (1999) Oxidative stress disrupts insulin-induced cellular redistribution of insulin receptor substrate 1 and phosphatidylinositol 3-kinase in 3T3-L1 adipocytes. J Biol Chem 274: 10595-10602

48. Abel ED, Shepherd PR, Kahn BB (1996) Glucose transporters and pathophysiologic states. In: LeRoith D, Taylor SI, Olefsky JM (eds) Diabetes mellitus. Lippincott-Raven, Philadelphia New York, pp 530-543

49. Skolnik EY, Marcusohn J (1996) Inhibition of insulin receptor signalling by TNF: potential role in obesity and non-insulin-dependent diabetes mellitus. Cytokine Growth Factor Rev 7: 161-173

50. Boden G (1997) Role of fatty acids in the pathogenesis of insulin resistance and NIDDM. Diabetes 46: 3-10

51. Paolisso G, Giugliano D (1996) Oxidative stress and insulin action: is there a relationship? Diabetologia 39: 357-363 